\title{
'N NUWE BENADERINGSMETODE IN VERBAND MET DIE STUDIE VAN DIE KONTAK TUSSEN BLANK EN BANTOE.
}

\section{Die Begrip Geskiedenis en Geskiedenisnavorsing.}

Die menslike verstand is daarop ingestel om feitelikhede te absorbeer en te onthou. Dit is 'n proses wat vanaf die oomblik van geboorte opgemerk word. Hierdie feiteversameling bly nie losstaande en dus niksseggende feite nie maar die menslike verstand is daarop ingestel om hierdie feitelikhede om te bou en tot 'n rasionale beeld daar te stel. Die feitelikhede wat so in die menslike verstand versintetiseer word is ' $n$ weerspieëling van die individu se mensomgewing. Die vraag ontstaan waarom die verstand die beeld dan op ' $n$ besondere wyse daarstel en nie op 'n ander wyse nie aangesien die losstaande feitereeks in letterlik duisende vorme daargestel kan word. Ons meen dat die besondere omgewing met sy eiesoortige waardebeginsels-godsdiens, kunsbeskouinge, ens.-die vormgewing van die beeld bepaal. Maar aangesien die wêreld uit verskillende kultuurstrukture bestaan, daarom is daar verskillende oordele by individue uit hierdie verskillende strukture. 'n Man uit Engeland sal 'n situasie verskillend interpreteer as 'n Duitser of Sjinees, en die ironie van die saak is dan dat die Engelsman, Duitser of Sjinees, ofskoon hul konklusies en interpretasie van die situasie wêreldwyd mag verskil, hulle al drie nie van die waarheid afgedwaal het nie!

Die geskiedenisstudent het daarby te doen met die interpretasie van 'n besondere moment of situasie in die verlede. 'n Moment of situasie as alleenstaande feitelikheid lewer egter geen probleem op nie. 'n Situasie kan egter nie 'n alleenstaande geisoleerde feitelikheid vorm nie, dit is cerder geleë in 'n kompleks gebeurtenissamehang wat die situasie voorafgegaan het en is deel van 'n reeks samehange of soos ons so graag sê "gevolge" wat weer na die toekoms reik.-Suid-Afrika sou nooit hierdie besondere kleurprobleem vertoon het as Jan van Riebeeck nie in 1652 aan die Kaap geland het nie. Indien hy vroeër of later geland het en indien die Kompanjiesbeleid in verband met byvoorbeeld immigrasie en kolonisasie anders vertoon het, dan sou die komplekse gebeurtenisse wat voortgevloei het uit die kontak tussen Blank en Bantoe anders vertoon het en sou die situasie nie gewees het wat dit vandag is nie.--'n Vroeëre landing sou beteken het dat die Blanke die Bantoe miskien eers op die Limpopo sou ontmoet het; indien Holland ten gunste van uitgebreide kolonisasie was, sou 
die bevolkingsbalans miskien ten gunste van die Blanke gewees het en sou ons nie die huidige situasie aantref waar ons oordeel en optrede ook tot 'n groot mate gefundeer is om die feit dat die Bantoe ons so ver in getalle oortref nie. Elke situasie is dus uniek en kan alleenlik uit homself verklaar word. Dit verraai dus bevooroordeeldheid as 'n liggaam soos die V.V.O. die toestand („situasie”) in Suid-Afrika beoordeel volgens maatstawwe wat toepasbaar is op besondere tradisionele situasies van dié lande anders as Suid-Afrika.

\section{Die Onderwys:}

Omdat ons oordeel gefundeer is op 'n bestaande situasie wat na die toekoms ontplooi en sy wortels het diep in die verlede in, kan ons onmoontlik nie die bestaande situasie na waarde peil as ons nie bewus is van sy historiese ontstaan en ontplooiing nie. So gesien is die studie van geskiedenis van onskatbare vormende waarde vir die mens.

Waar ons vandag te doen het met die sogenaamde ,kleur-probleem" kan ons nie en mag ons nie die studie van die kontak en saamleef van die twee groepe verontagsaam nie. Ek stem dus saam met dr. Eiselen dat 'n studie van die Bantoe vir die Blanke kind van lewensbelang is, maar vir die Bantoekind is dit van net so 'n groot belang om in sy geskiedenisles te verneem hoedat die kontak plaasgevind het. Waar die Suid-Afrikaanse Blanke se verlede tot dié van die Europese beskawing behoort, is dit goed dat hy veral ook nadruk lê op die Europese geskiedenis. By die Bantoe is dit effens anders. Sy antieke geestesverlede is op 'n geheel ander bodem, naamlik Afrika, te vind. Maar omdat hy ten dele 'n neiging vertoon om die Europese beskawingsgoedere oor te neem, moet daar in die meer gevorderde klasse 'n oorsigtelike kennis van die Europese historie tot hom grebring word.

\section{Die Taak van die Historikus:}

Ons het hierbo melding gemaak van die feit dat die historikus hom ten doel stel om 'n historiese situasie vas te stel en die om te skep in 'n werklikheidsbeeld wat in mindere of meerdere mate inpas by die historiese tydverloop wat sy konsentrasiepunt in die hede het.

Die vasstelling van die feit dat die Blankes sinds omstreeks 1740 aan die Visrivier in aanraking gekom het met die Bantoe, of dat daar 'n hele reeks oorloë teen die Xosas hierna gevoer is wat uiteindelik gelei het tot die algehele onderwerping van die Xosas en die totstandkoming van die Transkei en Ciskei met sy besondere administrasie en bestuur, óf dat die 
Trekkers na 1836 oor die Oranje getrek het en die Basoeto's in Basoetoland aangetref het met hier en daar 'n verspreide groepie tussen die Vaal en Oranje van wie hulle grond gekoop het, of dat Piet Retief en sy groep oor die Drakensberge is en Natal suid van die Tugela van Dingaan verkry het; of dat die Trekkers na 1840, nadat hulle Mzilikatze verslaan het, die Wes-Transvaal beset het en daarna na Oos-Transvaal en Noord-Transvaal is waar hulle geleidelik in aanrking gekom het met die verskillende Bantoegroepe in dié geweste soos die Venda, die Sjangaan, die Pedi, die Swazi en die Zoeloe; of dat die gebied tussen hierdie groepe heeltemal ontvolk was en dat die Blankes hul hier gevestig het nadat hulle óf hierdie gebied gekoop het óf geannekseer het as wedervergelding vir aanvalle op hulle, is maklik daar alle relevante dokumente in die verskillend argiewe te Kaapstad, Pietermaritzburg, Bloemfontein en Pretoria vir ons bewaar word deur ' $n$ bekwame en goedopgeleide argiefpersoneel.-Die navorser moet net die nodige geduld en tyd tot sy beskikking hê.

Ofskoon die vasstelling van 'n historiese feit reeds tot 'n fyne kuns ontwikkel het en uiteraard ook sy eie wetenskaplike metode het, hou die geskiedkundige hom primêr besig met die daarstelling of herskepping van 'n historiese werklikheidsbeeld of situasie binne 'n tydstroom. Die situasie en die waarom daarvan word opgebou uit 'n kennis wat die historikus van die besondere maatskappystruktuur moet verwerf voordat hy sy geïsoleerde verkreë feitereeks tot 'n geheelbeeld kan ombou. Dit beteken dus uiteraard dat die historikus ' $n$ diepgaande kennis van die agtergrond van so 'n kultuur of maatskappy moet hê.-Dit hang natuurlik ook af van die aard van sy onderwerp. Hy sal in elk geval vind dat hy op een oomblik 'n filosoof en die ander oomblik 'n taalkundige moet wees. Sonder' $n$ kennis van die aardrykskunde sal hy die maatskaplike struktuu wat hy bestudeer nie in ' $n$ ruimtelike verband kan plaas nie. Dan moet hy wat laasgenoemde betref, ook kan nagaan watter invloed die aardrykskunde op die struktuursamestelling en die houding van die individu binne die struktuur teenoor die buitewêreld gehad het. Die feit dat die Blanke en die Bantoe op dié eerste stadium van hul aanraking met mekaar geografies afgeslote groepe gevorm het, word vandag allerweë erken as die raison d'être van ons opvatting van geografiese afsondering tussen die twee groepe. Dit het begin by die Visrivier waar 'n rivier die geografiese skeiding tussen die twee kleurgroepe gevorm het.

Hierdie beleid kon voortgesit word in die O.V.S., Transvaal en Natal uit hoofde van die feit dat dit gelukkig so toegeval het dat die verskillende stamme in geïsoleerde geografiese gebiede aangetref is. Waar dit gebeur 
het dat die Bantoe later binne die politieke en ekonomiese struktuur van die Blanke ingetrek is, is hierdie begrip van territoriale afsondering omgevorm tot ' $n$ geestelike houding. Laasgenoemde sou egter nie die geval gewees het as die Blanke nie ook geestelik daartoe bereid was nie. Hy moes met ander woorde morele regverdiging soek vir sy aangenome houding. Die Calvinis vind sy morele regverdiging ten opsigte van hierdie houding in die Calvinistiese leer van soewereiniteit in eie sfeer.-Die historikus is daar dus ook 'n godsdiensfilosoof. Verder moet hy 'n diepgaande kennis dra van byvoorbeeld die numismatiek, (muntkunde), die sfagistiek (seëlkunde), heraldiek, argeologie, ens. En in ons land moet hy ook poog om 'n volkekundige te wees veral as hy 'n studie wil maak van die gevolge wat uit die kontak tussen Blank en Bantoe voortgevloei het, want hy sal verplig wees om sover menslik moontlik stap vir stap die innerlike verandering wat daar by die Blanke en Bantoemaatskaplike strukture - as ek dit so mag noem-plaasgevind het en wat tot gevolg gehad het die groei van 'n geheel ander struktuursamestelling, na te gaan. Hier wil ek dan ook die verskil van die werksaamhede van 'n volkekundige en 'n historikus as volg stel: Die volkekundige gaan na hoe die struktuur vertoon, terwyl die historikus stap vir stap moet nagaan hoedat die struktuur gegroei en ontwikkel het totdat dit so vertoon soos dit is.

\section{Die Kontakproblelem en die toekomstige Taak van die Historikus.}

Die wordingsproses van die struktuur wat bestudeer word deur die historikus word saamgestel deur 'n voorafgaande feitereeks op te bou bestaande uit geskrewe en ongeskrewe dokumente. Hierdie dokumente moet dan beskou word as die getuie van 'n volk of groep se verlede. Hierdie dokumente wanneer hulle geskrewe is, is geskryf deur privaat persone, administratiewe amptenare of politieke leiers van daardi besondere tyd en wat ook miskien persoonlik aanwesig was toe 'n besondere gebeurtenis plaasgevind het. As sodanig weerspieël die dokument dus die persoon se persoonlike gevoelens of die gevoelens van die groep waartoe hy of sy behoort. In die meeste gevalle beskerm dit die belange van die besondiere groep.

Hierdie dokumente of soveel daarvan as wat bewaar kan word, word in ons argiewe opgeberg en deur 'n opgeleide personeel gerangskik volgens onderwerp of aard. So byvoorbeeld as $u$ 'n studie wil maak van die naturelle-aangeleenthede in Transvaal in die vorige eeu, sal $u$ ten eerste die stukke van die Superintendent van Naturellesake gemerk S.N. moet deurgaan en van daar af deurwerk na die amptenare wat spesiaal belas was met Naturelleadministrasie. Dit sal onder andere insluit die Kom- 
mandant-Generaalstukke (K.G.) en die landdrosstukke van die verskillende distrikte asook die briewe van die veldkornette. As hierdie stukke deurgewerk is sal de navorser 'n taamlike goeie beeld kry van die kontak tussen Blank en Bantoe en die implikasies van daardie kontak, maar daardie dokumente is geskryf deur Blankes wat beskermend gestaan het teenoor die saak wat hulle gedien het en dit moet dus by implikasie as 'n eensydige voorstelling van die werklike toedrag van sake beskou word Wanneer die President van die Z.A.R. in 1876 die gedagte op skrif stel dat Sekhukhune, die opperhoof van die Pedi, regmatig as onderdaan van die Z.A.R. beskou moet word omdat hy toe hy vir Sekwati opgevolg het 'n olifantstand aan die landdros gestuur het en dat hierdie geskenk as tribuutbetaling beskou is, wat ' $n$ bewys is dat die Pedi hulle as onderdane van die Z.A.R. beskou het, dan moet die historikus, voordat hy hierdie gegewens aanvaar, eers deeglik nagaan of die stuur van 'n olifantstand by een besondere geleentheid volgens die gebruike en opvattings van die Bantoe, as tribuutbetaling beskou moet word. Wanneer 'n sendeling eers verwelkom word deur'n kaptein maar later weer verdryf word, sou dit verkeerd wees van die historikus om die getuienis van die sendeling, naamlik dat die besondere kaptein 'n ,goddelose barbaar' is, sonder meer te aanvaar. Die dokument word in so 'n geval alleenlik die aanvangspunt van waaruit die waarheid gesoek word, en die middel wat gebruik word om enigsins naby die waarheid te kom is in hierdie geval die volkekunde.

Miskien omdat ons kennis van die Bantoe in die verlede maar karig was, of miskien omdat so 'n wyse van ondersoek uiters moeilik was, het ons historici dusver oor die algemeen ongelukkig nie hierdie metode van analise met betrekking tot die vraagstuk van die kontak tussen Blank en Bantoe gevolg nie. Gevolglik lyk dit of daar 'n groot mate van waarheid in die bewering steek dat ons historici dusver alleenlik "The White Man's View" in hul geskrifte gehuldig het. Hierdie opvatting hou dié gevaar in naamlik dat alleenlik die "Black Man's View" deur ander historici gestel sal word terwyl die werklike ideaal is om die probleem te skilder teen die agtergrond van Blank-Bantoe samehange tegelyk. Dit sal ons vrywaar van'n oor-subjektiewe benadering van die vraagstuk.

Die gevolg van bogemelde was dat die Blanke historici die kontakprobleem sover moontlik vermy het in hul werk en dusver hoofsaaklik gekonsentreer het op die staatkundige of politieke geskiedenis van die Blanke alleen. Die resultaat van hul werksaamhede was dat ons vandag 'n taanlike duidelike beeld het van die politieke geskiedenis van die 
Blanke in Suid-Afrika. Veral die verhoudinge Boer-Brit het hul geïnteresseer en gelukkig vir hulle het die politieke kontak tussen hierdie twee groepe genoegsame gegewens opgelewer om ons belangrikste historici soos W. J. Leyds, Gustav Preller, C. J. Uys, P. J. van der Merwe, H. B. Thom, F. A. F. Wichmann, S. P. Engelbrecht, A. N. Pelzer, G. D. Scholtz, om maar net 'n paar te noem, besig te hou.

Hierdie historici kon egter uit die aard van die saak die Blanke se kontak met die Bantoe nie heeltemal vermy nie, aangesien die Bantoe dikwels as die twisappel tussen die Boere en Britte gedien het. Waar die Bantoe as groep egter geraak is, het dit heel dikwels as 'n sydelingse verwysing voorgekom of is dit heeltemal oppervlakkig behandel. Dit is wel waar dat as 'n mens die werke van Theal deurblaai, ' $n$ mens vind dat hy ook vele hoofstukke aan stamgeskiedenis wy, maar dit kom voor as losstaande hoofstukke wat by die gewone geskiedenis gevoeg is. Di1 vorm nie 'n integrale deel van die daargestelde geheelstruktuur nie juis omdat Theal op die feitelike gegewens aangewese was en nie díe gegewens in verband gebring het met die maatskaplike en stamstruktuur van die Blankes en Bantoe nie. Dit was dan ook hierteen naamlik dat Theal nic daartoe in staat was om die belangrike van die onbelangrike te skei nie juis omdat alle gegewens as eenvormige feitelike gegewens behandel is, dat ernstige kritiek teen hom as historikus ingebring is. Sy werk is in die opsig ' $n$ belangrike ensiklopediese naslaanbron, niks meer nie.

In die jongste jare is daar egter gevoel dat die kontak tussen Blank en Bantoe 'n ryke ondersoekingsveld is en dat in dié rigting met vrug gearbei kan word. Historici soos Agar-Hamilton, J. J. G. Grobbelaar, J D. Huyser, W. Kistner, D. J. Kotze en J. S. Marais het in hierdie rigting vrugbare veld gevind, maar die kontakprobleem is nog té veel vanuit die standpunt van die Blanke gesien. Titels soos die volgende dui onder andere op die eenvoudigheid van die benaderingswyse:

(i) The Native Policy of the Voortrekkers (Agar-Hamilton).

(ii) Die Vrystaatse Republiek en die Basoetovraagstuk (Grobbelaar).

(iii) Die Naturelle-Politiek van die Suid-Afrikaanse Republiek (Huyser).

(iv) Die Eerste Amerikaanse Sendelinge onder die Matabeles (Kotze, D. J.)

(v) Maynier and the First Boer Republic (Marais, J. S.).

(vi) The Native Policy of Benjamin Pine in Natal-1850-1855 (Lindsay Young). 


\section{'n Nuwe Rigting en die Toekoms:}

Gelukkig is daar een of twee historici wat begin besef het dat die dokument nie die absolute uitgangspunt kan wees wanneer daar oor die kontakprobleem geskryf word nie. Omdat die gedagte eintlik nuut is kan ook verwag word dat daar nog nie veel in hierdie nuwe rigting gedoen is nie. Een van die eerste Afrikaanse historici wat ten dele begin gebruik maak het van die nuwe rigting is dr. P. van Biljon,* wat sy debuut gemaak het met sy „Grensbakens tussen Blank en Swart in Suid-Afrika” in 1947. Van Biljon wou egter in eén werk 'n té groot veld dek met die gevolg dat ons uiteraard nie 'n werklik indringende analise en uiteensetting van die diepere reaksie-proses wat daar uit die kontak tussen Blank en Bantoe voortgevloei het, kry nie. Dit is aan die anderkant vir my verbasend dat Brookes se "History of Native Policy in South Africa" in sommige universiteite se volkekundeklasse so kritiekloos aanvaar word. Miskien moet dit gesoek word in die feit dat Brookes een van die weininges was wat in dié rigting gewerk het. Feit is egter dat Brookes, miskien omdat juis die veld wat hy wou dek so groot was en hy dit dus alleenlik oorsigtelik kon doen, beleidsrigtings alleenlik in die breë kon aandui en berus sy interpretasie van sommige van sy dokumentêre gegewens op geheel foutiewe gronde.

Gemelde twee skrywers het hul blootgestel aan kritiek juis omdat daar nie eers gewag is totdat enkele historici hul aandag op spesifieke afdelings van die kontakprobleem gevestig en dit in detail uitgewerk het nie.

Ek dink hier bevoorbeeld aan 'n onderwerp, om my weer tot die Transvaal te bepaal, soos die werksaamhede van die lokasiekommissie na 1882. Hier kan die vasstelling van elke lokasie en die moeilikhede wat daaruit voortgevloei het, met vrug nagegaan word. Verder vorm die Blanke se belastingstelsel en die reaksie van die Bantoe daarop, vrugbare veld vir studie. So kan 'n mens onderwerp na onderwerp noem, want die waarheid is dat die volkekundige hom dusver besig gehou het met etniese geskiedenis en die historikus het hom besig gehou met suiwer politieke geskiedenis. Die geskiedenis van die Bantoe nadat hy met die Blanke kontak gemaak het, is nog nie na behore geskryf nie.

Indien dit waar is soos ons aan die begin dit gestel het, naamlik dat die studie van geskiedenis vormend inwerk op die mens se lewenshouding

*(Sen ook van Rooyen, T. S.: Die Verhoudinge tussen die Boere, Engelse en Naturelle in Oos-Transvaal tot 1882.-Argiefjaarboek 1851, deel I). 
(en daar bestaan myns insiens geen argumente wat die teendeel oortuigend kan bewys nie), het dit dan nie tyd geword dat ons in die lig van voorafgaande ' $n$ deeglike studie maak van die kontak tussen Blank en Bantoe oor die voorafgaande 250 jaar nie? Is dit nie verkeerd om uitgebreide en omvattende kommissieverslae op te stel of om ekonomiespolitiek-sosiale studies te maak van die probleem soos hy hom teenswoordig vertoon terwyl die wetenskaplike basis waarop die houding van die wetenskaplike gebaseer is en dikwels deurslaggewend is vir sover dit sy gevolgtrekking betref, nie op 'n wetenskaplike en dus in hierdie geval historiese basis gefundeer is nie? Ook kan ek nie begryp hoedat die amptenaar wat belas is met die administrasie van 'n sekere stam tevrede moet wees met die kennis van die etniese geskiedenis van die besondere stam alleen nie, terwyl die skok wat die stam vanaf die oomblik van kontak met die Blanke ondergaan het, vir die amptenaar dikwels vreemd bly. Ons ken die Bantoe alleenlik tweeledig.-Ons ken sy stamgeskiedenis en ons ken hom soos hy vandag vertoon, maar die tussenperiode wat bepalend is vir sy houding van die hede, daarvan weet ons niks nie.-Ons besef somtyds ook nie watter groot moontlikhede in 'n dusdanige kennis opgesluit lê nie.

Pretoria.

T. S. VAN ROOYEN. 